Family Medicine and Community Health

\section{Global health training in Canadian family medicine residency programmes}

To cite: Jalan D, Morakis $\mathrm{H}$, Arya $\mathrm{N}$, et al. Global health training in Canadian family medicine residency programmes. Fam Med Com Health 2020;8:e000250. doi:10.1136/fmch-2019-000250

DJ and HM are joint first authors.

Check for updates

(c) Author(s) (or their employer(s)) 2020. Re-use permitted under CC BY-NC. No commercial re-use. See rights and permissions. Published by BMJ.

${ }^{1}$ Department of Family Medicine, McMaster University, Hamilton, Ontario, Canada

${ }^{2}$ Department of Emergency Medicine, University of British Columbia, Vancouver, British Columbia, Canada

${ }^{3}$ McMaster University, Hamilton, Ontario, Canada

${ }^{4}$ Department of Epidemiology, Biostatistics, Occupational Health and Public Health, McGill University, Montreal, Québec, Canada

${ }^{5}$ Department of Emergency Medicine, Queen's University, Kingston, Ontario, Canada

${ }^{6}$ Bridge to Health Medical and Dental, Toronto, Ontario, Canada ${ }^{7}$ Division of Emergency Medicine, Department of Family and Community Medicine, University of Toronto Faculty of Medicine, Toronto, Ontario, Canada

Correspondence to

Dr Divyanshi Jalan;

divyanshijalan@gmail.com

\section{ABSTRACT}

Objective Canadian family medicine (FM) residency programmes are responding to the growing demand to provide global health (GH) education to their trainees; herein, we describe the various GH activities (GHAs) offered within Canadian FM programmes.

Design A bilingual online survey was sent out to all 17 Canadian FM program directors (PDs) and/or an appointed GH representative.

Setting Online survey via Qualtrics

Participants All 17 Canadian FM PDs and/or an appointed GH representative.

Results The response rate was $100 \%$ and represented 3250 first-year and second-year FM residents across English and French Canada. All schools stated that they participate in some form of GHAs. There was variation in the level of organisation, participation and types of GHAs offered. Overall, most GHAs are optional, and there is a large amount of variation in terms of resident participation. Approximately one third of programmes receive dedicated funding for their GHAs, and two thirds wish to increase the scope/variety of GHAs.

Conclusion These results suggest nationwide interest in developing a workforce trained in $\mathrm{GH}$, but show great discrepancies in training, implementation and education.

\section{INTRODUCTION}

Koplan et al provide a definition of global health (GH) as: 'an area for study, research, and practice that places a priority on improving health and achieving equity in health for all people worldwide'. ' Family physicians are integral in addressing social determinants of health, as well as providing equitable care by advocating for marginalised and underserved populations. In Canada, rural healthcare coverage is an ongoing challenge. ${ }^{23}$ Furthermore, our First Nations, under-housed, refugee and immigrant populations frequently face healthcare inequities. $^{4-8}$

Canadian family medicine (FM) trainees have identified a need for a stronger presence of GH education in the FM curricula. ${ }^{9} 10$ The advantages conferred to residents who participate in GH electives include cultural sensitivity, greater interest in working with underserved patients and less reliance on expensive diagnostic technology. ${ }^{11}$ Although data in Canada are limited, a previous study from the USA estimated that $22 \%$ of FM residency programmes contained a GH concentration. ${ }^{12}$ At the undergraduate medical level, there is increasing interest from students to study global health as well as from curriculum developers to restructure and standardise courses. ${ }^{13}$ This could lead to a surge of interest in residency programmes that offer GHAs and could displace the acquisition of certain global health competencies to earlier in the medical training.

The nature and scope of global health activities (GHAs) are very broad and include both didactic and experiential learning. In 2010, the Ontario Global Health Family Medicine Curriculum Working Group identified the need for increasing the emphasis on GH competencies under each CanMEDS role during residency training. ${ }^{914}$ In the same year, Gupta et al summarised some data from a biannual questionnaire completed by FM resident members of the Section of Residents Council of the College of Family Physicians of Canada. ${ }^{9}$ At that time, $88 \%$ of Canadian FM residency programmes had some formal GH curriculum, with most schools devoting $<10$ hours to the subject over 2 years of training. For further GH training, Canadian FM residents can apply to enhanced skills programmes, occurring during postgraduate year 3, offered at 6 of 17 Canadian medical schools. A literature review showed that elective courses are the most widely used method of teaching trainees in $\mathrm{GH}^{15}$ with international electives being frequently described in the literature. The lack of standardisation of GH education is such that it is challenging to assess other methods of GH training, such as in research or formal course work within Canada. ${ }^{15}$

Although Redwood-Campbell et al began to map $\mathrm{GH}$ competencies in $\mathrm{FM},{ }^{10}$ to our knowledge, there has been no study surveying the entire landscape of GH education in Canadian 
FM residency programmes. Herein, we provide a snapshot of FM GH training across the country, with GHAs defined as any lectures, seminars, research or electives that focus on education around GH topics in local or international settings. ${ }^{16}$

\section{METHODS}

The 85-question survey was developed and piloted by a group of Canadian and American clinicians involved in GH education affiliated with the Workforce Subcommittee of the Consortium of Universities for Global Health (CUGH). The survey content was modified based on recommendations post pilot and adjusted for content and face validity.

FM residency programmes directors (PDs) were identified through the CaRMS website. The survey was addressed to PDs, and they were invited to appoint a GH representative to complete the survey or to complete the survey themselves. A list of GH representatives, (up to) one per programmes, were also identified through each of the 17 Canadian FM residency programmes' websites and confirmed through a network of contacts and copied on survey invitation emails. Respondents were requested to omit information regarding the third-year residency programmes in $\mathrm{GH}$.

An email invitation to the self-administered survey detailing the purpose of the study was sent to each participant via Qualtrics, an online survey software, and at least two email reminders were sent. The survey was distributed in English and French. Data were analysed through Qualtrics.

\section{RESULTS}

Our survey had a $100 \%$ response rate and an $88 \%$ completion rate. Six PDs answered the survey and the remaining 11 of 17 surveys were answered by an appointed GH representative.

All 17 Canadian FM residency programmes claimed to offer one or more GHAs [table 1]. Overall, most GHAs are optional, and there is variation in terms of resident participation. The Northern Ontario School of Medicine, Queen's University, and the universities of Saskatchewan, Alberta and Calgary reportedly had the highest rates of resident participation at $76 \%-100 \%$.

Of Canadian FM residency programmes, $41 \%$ identified that their GH training is coordinated formally by one or multiple types of GH offices, including an office in the FM programmes, an office that oversees postgraduate medical education at their institution, and/or an office for the undergraduate school of medicine at their institution. The remaining reported having either a faculty member and/or residents responsible for organising GHAs.

All programmes claim to offer periodic seminars or lectures, although they vary in terms of their frequency. Didactic GHAs are offered for $<4$ hours per month at $76 \%$ of the programmes, for $5-10$ hours per month at $12 \%$ of the programmes and for $10-20$ hours per month at $6 \%$ of the programmes.
Domestic GH rotations involve residents working with various disadvantaged populations including indigenous, homeless individuals/those living in poverty, LGBTQ, refugees, immigrants and/or persons with substance use disorders [figure 1]. Currently, $76 \%$ of FM programmes claim to offer $\mathrm{GH}$ training related to indigenous health. Domestic rotations are reportedly offered by $88 \%$ of the FM programmes, however, they are only mandatory at $12 \%$ of programmes.

Canadian FM programmes send trainees to rural areas in the regions surrounding their school. For instance, Memorial University of Newfoundland offers five different streams for their residency programmes, two of which are in Labrador and Nunavut offering residents exposure to rural, under-resourced communities with a predominantly First Nations population. Schools based in larger centres such as the University of Toronto, McMaster, University of Sherbrooke and the University of British Columbia involve their residents in inner-city patient care such as in addictions medicine, harm reduction, LGBTQ health and refugee health. McMaster, for example, offers a pilot curriculum in social medicine that offers trainees the opportunity to work at partner sites at addictions centres, refugee clinics and shelter health. Northern Ontario School of Medicine (NOSM) partners directly with First Nations management to offer placements on First Nations reserves.

International rotations are reportedly offered by $82 \%$ of programmes, and of these, $86 \%$ are between 4 and 8 weeks in duration. Most international rotations occur in lowincome and middle-income countries [figure 2], with $18 \%$ of rotations occurring in countries that are considered to be in the lowest 20 with regards to gross domestic product (GDP) per capita. Of the international rotations listed by the programmes, $57 \%$ of placements occur in countries where healthy life expectancy at birth is below 60 years. Programmes report a degree of reciprocity for $82 \%$ of international rotations, whether it be a resident or medical educator exchange or training of educators at partner sites.

Figure 3 depicts locations for international rotations and partner sites for FM programmes. At the University of Ottawa, residents are able to propose a self-designed international rotation in their second year of training outside of the programmes' partner sites.

Of FM programmes, $53 \%$ identified that they offer research or scholarly projects related to GHAs. Specific topics identified by the programmes were transgender health, international sexual education, refugee health and the opiate crisis. The University of Toronto reported that two thirds of the research projects and quality improvement research conducted at St Michael's hospital are focused on vulnerable populations.

Only $35 \%$ of FM programmes identified that they receive dedicated funding for their GHAs. With regards to future directions, $65 \%$ of FM programmes identified that they wish to increase the scope/variety of GHAs, whereas $29 \%$ stated that they foresee no changes in the training offered. When asked to specify what changes they would 


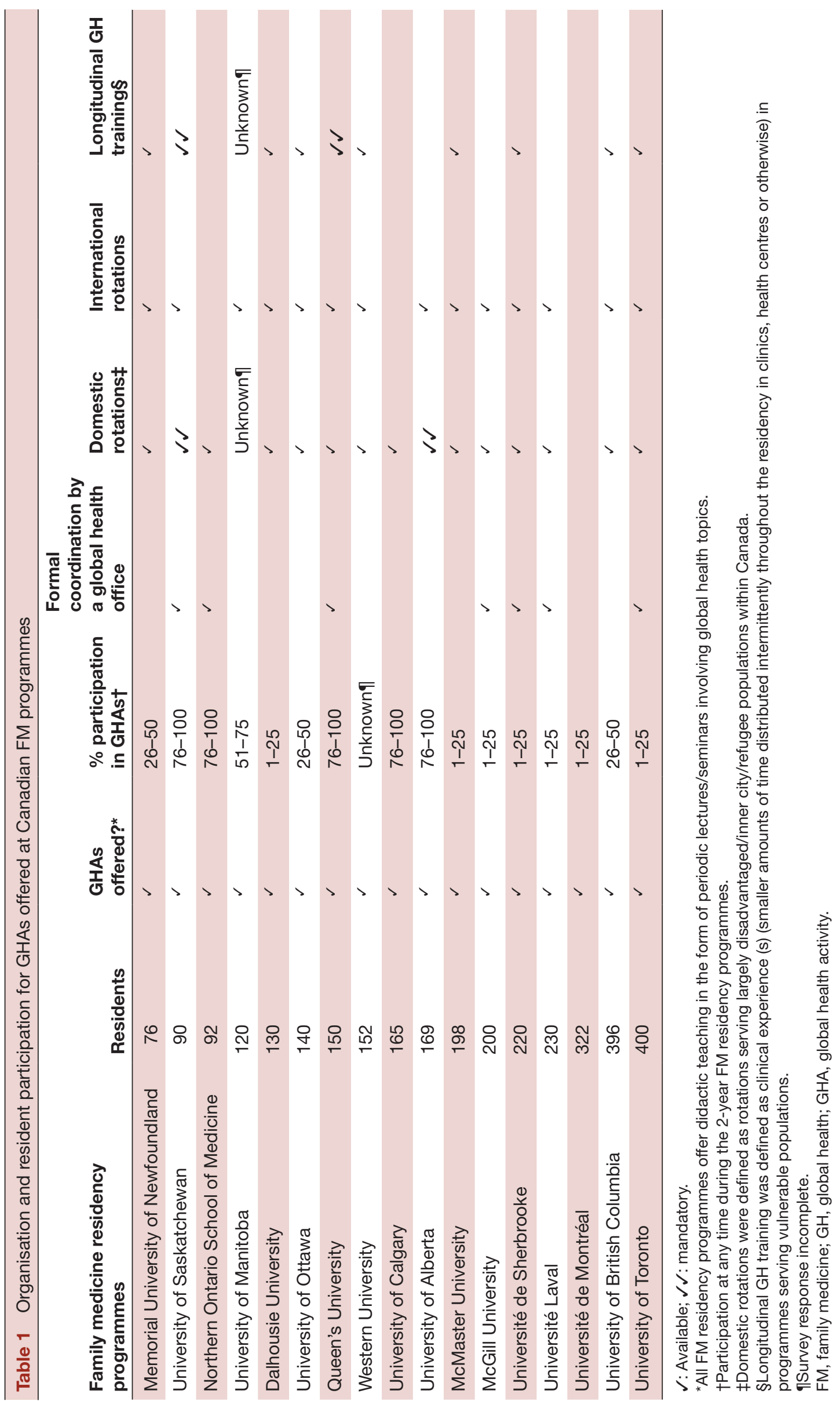




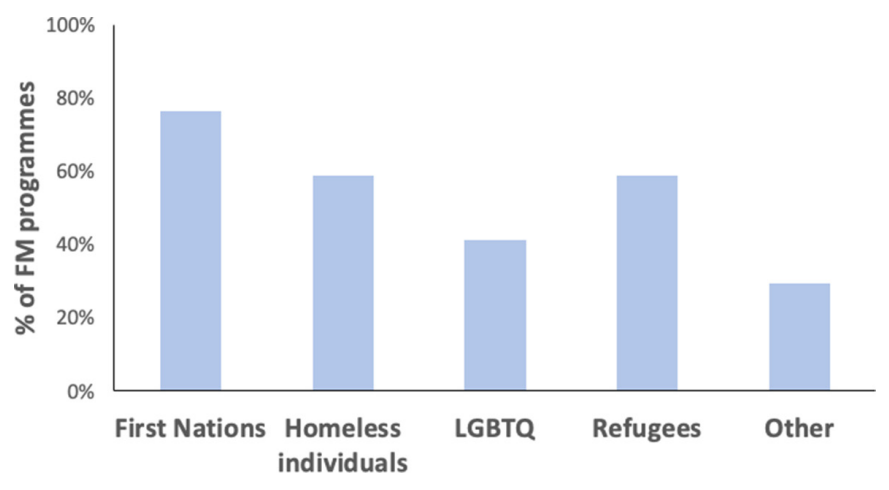

Figure 1 Diasdvantaged populations that residents are exposed to during domestic rotations. Other populations identified by FM programmes include persons living in poverty, immigrants and persons with substance use disorders. FM, family medicine.

like to see in the GHAs offered by their programmes, four programmes identified the need to incorporate more exposure to indigenous health.

\section{DISCUSSION}

Our study is the first of its kind to map the GHAs of all FM programmes across Canada.

All schools stated that they participate in some form of GHAs. There was variation in the level of organisation, level of participation, types of GHAs and funding available for GHAs. Organised exposure to domestic vulnerable populations was offered by $88 \%$ of programmes but was only mandatory in $12 \%$ of programmes. Two thirds of programmes indicated that they wished to increase the scope/variety of GHAs, and four programmes wished to increase exposure to indigenous health.

In 2011, Canadian Family Medicine programmes implemented the competency-based Triple C Curriculum, which includes recommendations to prepare learners to provide patient-adapted care in vulnerable populations. ${ }^{17}$ In our study, it is encouraging to see that currently, all Canadian FM residency programmes claimed to have some type of GHAs. Our study found that GH training is formally coordinated through a central office at $41 \%$ of FM programmes. The roles of a centralised GH

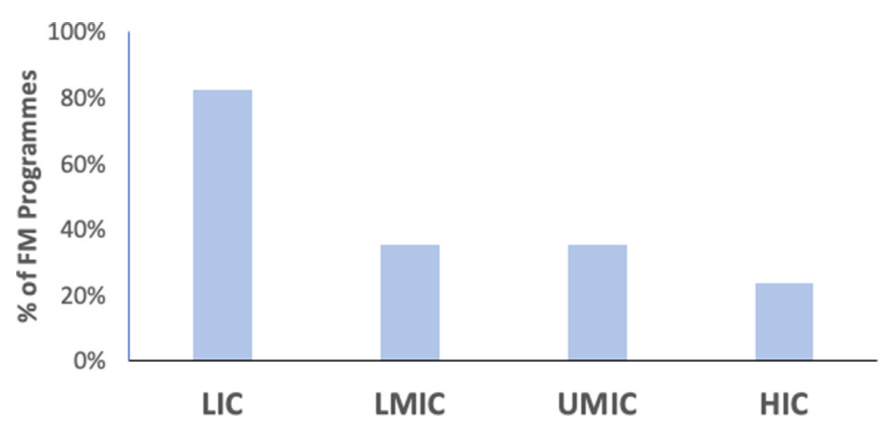

Figure 2 International rotations by World Bank Income Economy Classification. FM, family medicine; HIC, highincome country; LIC, lower-income country; LMIC, lowermiddle-income country; UMIC, upper-middle-income country.

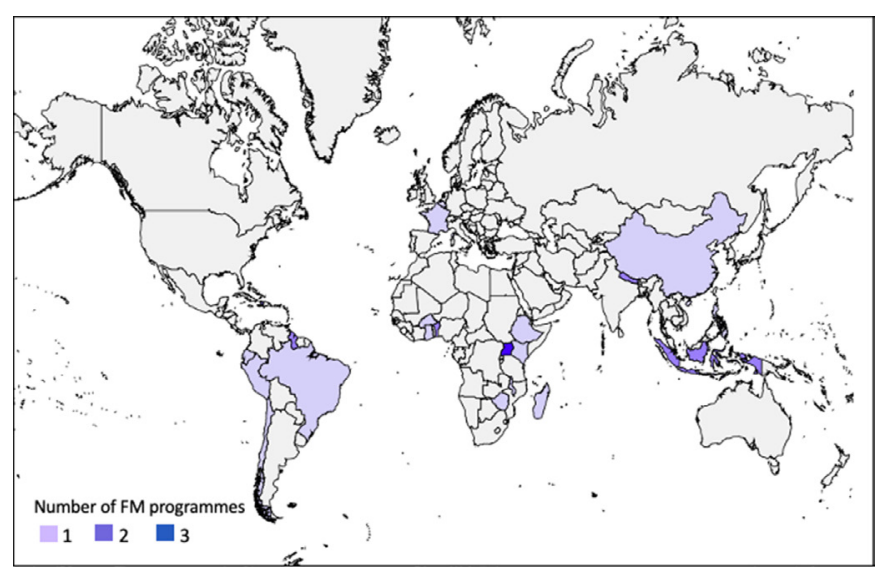

Figure 3 Locations for international rotations and partner sites for Canadian FM programmes. FM, family medicine.

office-including coordinating resources for trainees, developing content and curriculum, building partnerships with local and international communities-have been commented on in the literature, however, research on the effectiveness of such offices is limited. ${ }^{18}$

In the 2015 Canadian Truth and Reconciliation Commission, recommendations were made for cultural competency and human rights training for healthcare trainees. ${ }^{5}$ Appropriately $76 \%$ of FM residency programmes are responding to these needs by offering placements on First Nations reserves, having residents work directly with urban indigenous patients and supporting research about indigenous health.

There is a great disparity in the shape and function of international medical electives, including length, competencies, pre-departure training and otherwise. ${ }^{19}$ It has been shown that both students and residents who have participated in international electives are more likely to pursue primary care and serve marginalised populations. ${ }^{20}$ Our study identified that of the programmes that offer international rotations, $86 \%$ offer them for between 4 and 8 weeks in duration. A recent study found that the average length of short-term experiences in global health (STEGH) was between 2 and 4 weeks or $>12$ weeks. ${ }^{21}$ Sources do not agree on the ideal length, some report that 6 weeks may be considered too short, and 2 or 3 months may be more valuable, ${ }^{22}$ whereas others state that the duration is less important than the structure that supports it. ${ }^{20}$ Ways to mitigate harm and ensure the success of STEGH centre on ensuring adequate pre-departure training and emphasis on learning about comparative health systems and GH challenges in a respectful manner. The Canadian Federation of Medical Students published pre-departure guidelines in 2008 that could be applied to FM trainees. ${ }^{23}$ At the time of publication, 11 of 17 undergraduate programmes had an established pre-departure training programmes, with 3 additional programmes planning to implement a programmes the following year. ${ }^{23}$ Surveys show that host lower-middle-income country communities would value equal opportunities for their staff and residents to train 
in high-income countries. ${ }^{24}$ It is encouraging to see that $82 \%$ of established Canadian resident international electives have an exchange component or Canadian faculty teaching for the host community medical residents and/ or staff. When developing these international GH partnerships, we encourage programmes to refer to a framework for medical service trips that has been proposed following a literature review and stakeholder consensus to ensure ethical and productive experiences for both learners and the host community. ${ }^{25}$ The 18 recommendations centred around the domains of sustainability, education, efficiency, impact and safety, preparedness and cost-effectiveness would be applicable in international and domestic GH settings. ${ }^{25}$

There are several limitations to this study. Due to its self-administered survey design, responses may not fully quantify or represent the true nature of activities in GHAs available at the programmes. Responses may also vary in accuracy depending on whether the survey was answered by the PD of the FM programmes as compared with an assigned GH representative, however, given the PD has access to all training content and staff, this risk is well mitigated. Several Canadian FM programmes have multiple training sites, each with a slightly different curriculum; as such, unified response from one representative was identified as challenging by some of the respondents. This highlights the importance of centralised coordinating bodies, in particular at larger institutions. Furthermore, several programmes allow residents a self-designed component to their GH training which is difficult to capture without resident input.

\section{CONCLUSIONS}

Given recent trends towards nationalism and closed borders, it is encouraging that every FM programmes across Canada offers some form of GHA. Family doctors, typically the initial entry point into the healthcare system, have a unique opportunity to enhance their role in improving health access and outcomes for all people. The results of our study show that programmes across Canada support this conclusion.

Looking to the future, we suggest that research explore resident's exposure to $\mathrm{GH}$ training at the undergraduate level, their satisfaction with the GH training, effect on the resident appreciation of the social determinants of health and the relevance of this training to their future practice in GH. Further collaboration and discussion between residency programmes across Canada would give the opportunity to identify strategies that have been successful and that can be replicated nationwide to ensure the most competent and effective FM workforce for Canada and beyond.

\section{Twitter William Cherniak @williamcherniak}

Acknowledgements The authors would like to acknowledge all the survey respondents from Family Medicine residency programmes across Canada.

Collaborators Dr. Thomas Hall.

Contributors All authors contributed to the preparation of this manuscript equally.
Funding The authors have not declared a specific grant for this research from any funding agency in the public, commercial or not-for-profit sectors.

Competing interests None declared.

Patient consent for publication Not required.

Provenance and peer review Not commissioned; externally peer reviewed.

Data availability statement All data relevant to the study are included in the article. The survey used for this study is available upon reasonable request from divyanshijalan@gmail.com. Additional survey responses that have not been published will be shared with survey respondents only.

Open access This is an open access article distributed in accordance with the Creative Commons Attribution Non Commercial (CC BY-NC 4.0) license, which permits others to distribute, remix, adapt, build upon this work non-commercially, and license their derivative works on different terms, provided the original work is properly cited, appropriate credit is given, any changes made indicated, and the use is non-commercial. See: http://creativecommons.org/licenses/by-nc/4.0/.

ORCID iD

William Cherniak http://orcid.org/0000-0003-3001-2400

\section{REFERENCES}

1 Koplan JP, Bond TC, Merson MH, et al. Towards a common definition of global health. The Lancet 2009;373:1993-5.

2 Martin D, Miller AP, Quesnel-Vallee A, et al. Canada's universal health-care system: achieving its potential. The Lancet 2018;39:1718-35.

3 Canadian Institute for Health Information. Supply, distribution and migration of physicians in Canada, 2016: data tables, 2017. Available: https://secure.cihi.ca/estore/productFamily.htm?pf= PFC3537 \& lang=en\&media $=0$ [Accessed 30 Jun 2018].

4 Montreal (QC): Canadian Council for Refugees. Refugee health survey by province and by category, 2015. Available: http://ccrweb. $\mathrm{ca} /$ sites/ccrweb.ca/files/ccr-refugee-health-survey-public.pdf [Accessed 27 Aug 2018].

5 Winnipeg (MB): Truth and Reconciliation Commission of Canada. Truth and reconciliation commission: calls to action, 2015. Available: http://www.trc.ca/websites/trcinstitution/File/2015/Findings/Calls_to Action English2.pdf [Accessed 27 Aug 2018].

6 Kalich A, Heinemann L, Ghahari S. A scoping review of immigrant experience of health care access barriers in Canada. $J$ Immigrant Minority Health 2016;18:697-709.

7 Campbell DJT, O'Neill BG, Gibson K, et al. Primary healthcare needs and barriers to care among Calgary's homeless populations. BMC Fam Pract 2015;16:139.

8 Hwang SW, Ueng JJM, Chiu S, et al. Universal health insurance and health care access for homeless persons. Am J Public Health 2010;100:1454-61.

9 Gupta A, Talavlikar R, $\mathrm{Ng} \mathrm{V}$, et al. Global health curriculum in family medicine: resident perspective. Can Fam Physician 2012;58:143-6.

10 Redwood-Campbell L, Pottie K, Arya N, et al. Ontario family medicine residency global health curriculum development project: a preliminary report by the Ontario global health family medicine curriculum Working group. Hamilton, ON: Ministry of Health and Long-Term Care, 2010.

11 Drain PK, Primack A, Hunt DD, et al. Global health in medical education: a call for more training and opportunities. Acad Med 2007;82:226-30.

12 Kerry VB, Walensky RP, Tsai AC, et al. Us medical specialty global health training and the global burden of disease. $J$ Glob Health 2013;3:1-9.

13 Arya AN, Evert J. Global health experiential education: from theory to practice. Routledge, 2017. https://books.google.ca/books?id= SBPPAQAACAAJ

14 The Royal College of Physicians and Surgeons of Canada. CanMEDS: Better standards, better physicians, better care [Internet], 2018. Available: http://www.royalcollege.ca/rcsite/canmeds/ canmeds-framework-e [Accessed 27 Aug 2018].

15 Liu Y, Zhang Y, Liu Z, et al. Gaps in studies of global health education: an empirical literature review. Glob Health Action 2015;8:25709.

16 Evert J, Stewart C, Chan K, et al. Developing residency training in global health: a guidebook. San Francisco: Global Health Education Consortium, 2008. https://globalhealtheducation.org/PublicDocs/ GHEC\%20Residency\%20Guidebook.pdf 
17 Section of Teachers, The College of Family Physicians of Canada. Triple C competency-based curriculum - report of the Working group on postgraduate curriculum review - Part 1. Mississauga: Section of Teachers, The College of Family Physicians of Canada, 2011. https:// www.cfpc.ca/uploadedFiles/Education/_PDFs/WGCR_TripleC_ Report_English_Final_18Mar11.pdf

18 Quinn TC. The Johns Hopkins center for global health: transcending borders for World health. Acad Med 2008;83:134-42.

19 Cherniak WA, Drain PK, Brewer TF. Education objectives of international medical electives - a narrative literature review. Acad Med 2013;88:1778-81.

20 Drain PK, Holmes KK, Skeff KM, et al. Global health training and international clinical rotations during residency: current status, needs, and opportunities. Acad Med 2009;84:320-5.
21 Cherniak W, Latham E, Astle B, et al. Visiting trainees in global settings: host and partner perspectives on desirable competencies. Ann Glob Health 2017;83:359-68.

22 Loh LC, Cherniak W, Dreifuss BA, et al. Short term global health experiences and local partnership models: a framework. Global Health 2015;11:50.

23 Anderson K, Bocking N. Preparing medical students for electives in low-resource settings: a template for national guidelines for predeparture training. 1st edn. Ottawa: AFMC Global Health Resource Group and CFMS Global Health Program, 2008.

24 Kung TH, Richardson ET, Mabud TS, et al. Host community perspectives on trainees participating in short-term experiences in global health. Med Educ 2016;50:1122-30.

25 Dainton C, Chu CH, Gorman C, et al. Development of a theoretical framework for assessment of quality of primary care medical service TRIPS in Latin America. Int J Public Health 2019;64:333-42. 